\title{
Efficient abrasive water jet milling for near-net-shape fabrication of difficult-to-cut materials
}

\author{
Eckart Uhlmann ${ }^{1,2} \cdot$ Constantin Männel $^{1} \cdot$ Thomas Braun $^{1}$
}

Received: 2 June 2020 / Accepted: 9 September 2020 / Published online: 2 October 2020

(C) The Author(s) 2020

\begin{abstract}
The utilization of materials with high strength to density ratio enables efficiency improvements and is therefore demanded for many applications, particularly in the aerospace and other mobility sectors. However, the machining of these typically difficult-to-cut materials poses a challenge for conventional manufacturing technologies due to the high tool wear. Abrasive water jet (AWJ) machining is a promising alternative manufacturing technology for machining difficult-to-cut materials, since the tool wear is low and material independent. However, AWJ machining is limited regarding the producible geometries when conducting cuts through a material. This limitation can be resolved with AWJ milling operations which on the other hand are time-consuming. To approach this challenge, an enhanced AWJ milling operation is presented and investigated in this paper with the aim to expand the producible geometries. This operation consists of two kerfs, inserted from different sides of the workpiece, which intersect at their kerf ground. Consequently, a piece of material is separated without the cut material being entirely chipped. Thus, the operation possesses a high aggregated material removal rate. The investigations presented in this paper show and evaluate the effects that occur during the milling of kerfs with variable depths on titanium aluminide TNM-B1. Furthermore, a method to compensate these effects is introduced and thus the producible geometries for effective AWJ milling could be enhanced.
\end{abstract}

Keywords Abrasive water jet $\cdot$ Near-net-shape fabrication $\cdot$ Titanium aluminide $\cdot$ AWJ milling

\section{Nomenclature}

$\dot{m}_{A} \quad$ Abrasive flow rate

$\alpha_{c}^{\prime} \quad$ Adjusted angle of cut

$\alpha_{\mathrm{c}(\mathrm{y})} \quad$ Constant angles of cut

$\alpha_{\mathrm{c}, \text { real }} \quad$ Actual cutting angle

$\alpha_{\mathrm{c}} \quad$ Angle of cut

$\alpha_{\mathrm{jf}, \mathrm{a}} \quad$ Opening angle of the jet forerun for concave shapes

$\alpha_{\mathrm{jf}, \mathrm{x}} \quad$ Opening angle of the jet forerun for convex shapes

$\alpha_{\mathrm{jl}, \mathrm{a}} \quad$ Opening angle of the jetlag for concave shapes

$\alpha_{\mathrm{j} 1, \mathrm{x}} \quad$ Opening angle of the jetlag for convex shapes

AWJ Abrasive water jet

$c_{1} \quad$ Kerf development coefficient 1

$c_{2} \quad$ Kerf development coefficient 2

Constantin Männel

maennel@iwf.tu-berlin.de

1 Technische Universität Berlin, Institute for Machine Tools and Factory Management (IWF), Berlin, Germany

2 Institute for Production Systems and Design Technology (IPK), Fraunhofer-Gesellschaft, Berlin, Germany $c_{3} \quad$ Kerf development coefficient 3

$c_{\mathrm{p}} \quad$ Power coefficient

CFRP Carbon fibre-reinforced polymers

CMC Ceramic matrix composites

$d_{\mathrm{f}} \quad$ Focus tube diameter

$d_{\mathrm{J}} \quad$ Jet diameter

$d_{\mathrm{K}, \mathrm{c}} \quad$ Average cumulated kerf depth

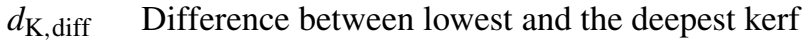
depth

$d_{\mathrm{K}, \max } \quad$ Maximum kerf depth

$d_{\mathrm{K}, \min } \quad$ Minimum kerf depth

$d_{\mathrm{K}, \mathrm{m}} \quad$ Measured kerf depth

$d_{\mathrm{K}, \mathrm{p}} \quad$ Kerf depths on the primary target part

$d_{\mathrm{K}, \mathrm{s}} \quad$ Kerf depths on the secondary target part

$d_{\mathrm{K} 1} \quad$ Kerf depth for one pass

$d_{\mathrm{K}} \quad$ Kerf depth

$d_{\mathrm{o}} \quad$ Orifice diameter

$e \quad$ Deviation of the kerf depth to the target kerf

EDM Electrical discharge machining

$f_{\mathrm{a}} \quad$ Concave geometry factor

$f_{\mathrm{x}} \quad$ Convex geometry factor

fps $\quad$ Frames per second 
$l_{\mathrm{d}} \quad$ Depth of specimen

$l_{\mathrm{f}} \quad$ Focus tube length

$l_{\mathrm{s}} \quad$ Stand of distance

$l_{\mathrm{W}} \quad$ Length of specimen

MMC Metal matrix composites

$p \quad$ Water pressure

$p_{\mathrm{W}} \quad$ Workpiece position

PTP Primary target part

$r \quad$ Radius of shape

$r_{\mathrm{vf}} \quad$ Relative velocity

$s \quad$ Standard deviation

STP Secondary target part

TNM-B1 Gamma-TiAl Ti-43,5Al-4Nb-1Mo 0,1B

$v_{\mathrm{f}} \quad$ Feed speed

$z \quad$ Number of passes

\section{Introduction}

The AWJ technology inheres some desirable advantages over the conventional cutting processes milling, drilling and turning. These are, for example, the independence of the tool wear from the workpiece material, the absence of repercussions of the material surface on the cutting ability of the AWJ and the possibility to cut almost all kinds of materials brittle [1] and ductile [2]. Thus, AWJ is a promising technology, particularly to manufacture difficultto-cut materials such as metal matrix composites (MMC), nickel base alloys [3], titanium aluminides [4], ceramics, ceramic matrix composites (CMC) [5] or carbon fibrereinforced polymers (CFRP) [6]. Since the application of such materials is continuously increasing due to the demands of light weight design and efficiency requirements, the AWJ technology has attracted further attention and the market is continuously growing over the last years. However, the attainable surface quality of AWJ machining is limited. If a very high surface roughness is required for example for aerodynamic parts, AWJ machining might not fulfil these requirements. Consequently, a finishing operation, e.g. grinding, is required [7]. Therefore, the investigated AWJ technology is considered to be a near-netshape fabrication technology.

Conventionally, the AWJ technology is a cutting process for sheet metal and other flat materials (Fig. 1a) [1]. However, since the producible geometries of this process are limited, further AWJ operations have been proposed and studied. Turning, milling and drilling [8] are some of the processes that can be adopted with the AWJ and are applied today. Milling without masks, shown in Fig. 1b, is a process of particular interest since this operation enables further geometrical design leeways [9]. AWJ milling operations have been tested and qualified for a number of materials including titanium aluminides [10]. To apply AWJ milling, the process parameters are usually changed. The water pressure $p$ is reduced, the feed speed $v_{\mathrm{f}}$ and the number of passes $z$ are increased. These parameter settings generate a better surface quality but reduce the material removal rate. Because of the high feed speed acceleration and deceleration procedures of the manufacturing machine have to be considered for this operation [11]. To quickly design AWJ milling operations, van Bui et al. [12] have suggested the use of the Gaussian curve and its superposition to describe the material removal of the operation. Although a lot of fundamental and application knowledge about AWJ milling operations has been achieved [13], the application of the technology for industrial purposes is limited. The low use of the technology might be due to the decreased material removal rate and thus the long manufacturing time [9]. In order to increase the efficiency of the AWJ milling process, the superposition of two kerfs, cut from different sides of the workpiece (Fig. 1c), was suggested [14] and studied in detail by Faltin [15] and in previous investigations regarding the modelling possibilities [4], the implementation [16] and the cost-effectiveness [17] of the approach.

Faltin [15] demonstrated the feasibility of the approach and provided fundamental knowledge for its application. Furthermore, a model has been introduced to effectively design these AWJ milling operations in a previous work [4]. Following this approach, the AWJ milling operations can be designed and predicted by the use of a power coefficient $c_{\mathrm{p}}$ and three coefficients $c_{1}$ to $c_{3}$ for the development of a kerf over the number of passes $z$. The formulae can be converted to formula 1, which calculates the feed speed $v_{\mathrm{f}}\left(d_{\mathrm{K}}\right)$ necessary to attain a certain kerf depth for a given water pressure $p$ and the number of passes $z$.

$v_{\mathrm{f}}\left(d_{\mathrm{K}}\right)=\frac{p \cdot c_{\mathrm{p}} \cdot d_{\mathrm{K}}(z)}{d_{\mathrm{K}} \cdot d_{\mathrm{K}}\left(z_{1}\right)}=\frac{p \cdot c_{\mathrm{p}} \cdot\left(c_{1}+c_{2} \cdot z+c_{3} \cdot z^{2}\right)}{d_{\mathrm{K}} \cdot\left(c_{1}+c_{2}+c_{3}\right)}$

Both the modelling study [4] and the analysis by Faltin [15] consider only the cutting of constant kerfs depths (Fig. 1c). In order to further increase the producible geometries and to enhance the effectiveness of the presented efficient AWJ milling operation, it is necessary to adjust the kerf depth depending on the part design. Consequently, kerfs with variable kerf depths are investigated in this paper. Kerfs with variable kerf depths are necessary, e.g. for the manufacturing of a turbine blade. The operations of interest are cuts A and B (Fig. 1d). Once all cuts can be designed, the entire turbine blade including the blade and the fir tree connection can be manufactured by the efficient AWJ milling operation. In this study, titanium aluminide is considered workpiece material. This material is one of the above-described high-performance but difficult-to-cut materials. This material resists high stresses as well as high temperatures while offering a better strength 


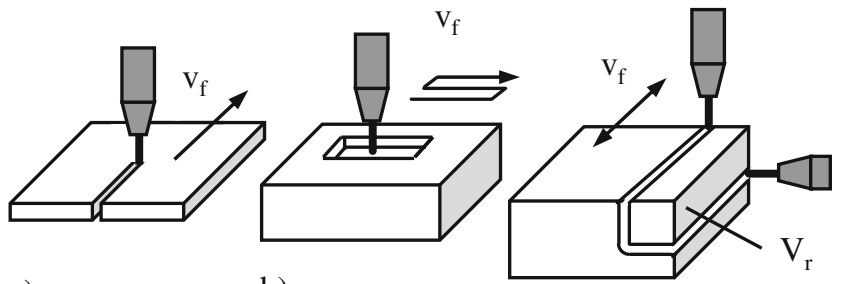

a) b)

c)

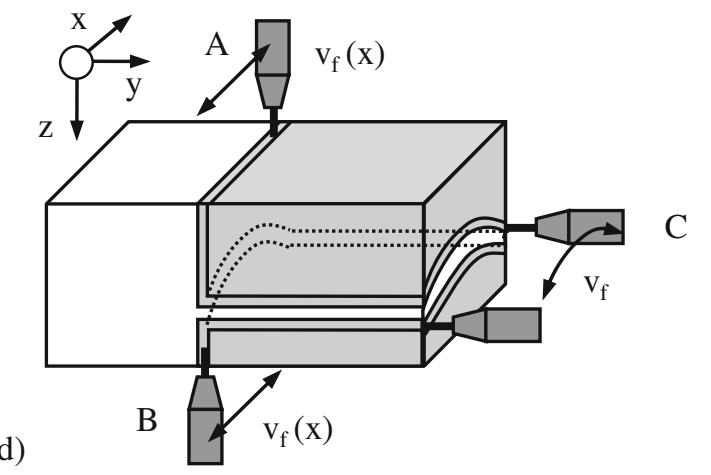

Fig. 1 AWJ process variations: a cutting; b controlled depth milling; c segment removal by controlled depth cutting; $\mathbf{d}$ machining of a turbine blade using segment removal by controlled depth cutting

to density ratio than nickel base alloys and thus promises further improvements in light weight design. Furthermore, titanium aluminides are partly used in gas turbines already. However, the manufacturing of titanium aluminides using conventional cutting remains a challenge [15]. Hence, the application of titanium aluminides might be promoted by a more efficient manufacturing technology.

To achieve variable kerf depths $d_{\mathrm{K}}(x)$, the number of passes $z$, the water pressure $p$ or the feed speed $v_{\mathrm{f}}$ can be adjusted. Since the feed speed $v_{\mathrm{f}}\left(d_{\mathrm{K}}\right)$ can be adjusted very precisely, this parameter is tested to ensure a homogeneous jet at all times. In the previous investigations [4], the use of an angle of cut $\alpha_{\mathrm{c}}$ for a milling operation has shown a distinct influence on the kerf parameters. Comparable effects must be expected for kerfs with variable kerf depths $d_{\mathrm{K}}(x)$ as well.

\section{Experimental setup}

In order to investigate the possibility of cutting kerfs with variable kerf depths $d_{\mathrm{K}}(x)$, a series of experiments were carried out. The investigation comprised a detailed analysis of the water jet's behaviour and its deflection when cutting the desired concave and convex shapes. First, the general behaviour of the water jet was examined and visualized with a high-speed camera to better understand the fundamental effects occurring during the cutting. Secondly, an analogy test was performed in order to evaluate the strength of these effects. Third, a test plan was carried out cutting the desired kerfs with variable depths.

All experiments were performed by a robot-guided water jet machine type HRX 160 L by STM STEINMoser GMBH, Schweinfurt, Germany (Fig. 2c). The cutting head was equipped with an orifice with a diameter of $d_{\mathrm{o}}=0.25 \mathrm{~mm}$, and a focus tube with a length of $l_{\mathrm{f}}=76.2 \mathrm{~mm}$ and a diameter of $d_{\mathrm{f}}=0.76 \mathrm{~mm}$. A stand of distance of $l_{\mathrm{s}}=2 \mathrm{~mm}$ was applied for all tests (Fig. 2a). Garnet mesh size 120 of GMA GARNET (EUROPE) GMBH, Hamburg, Germany, was used to cut the test material titanium aluminide, type Gamma-TiAl Ti-43,5Al-4Nb-1Mo 0,1B (TNM-B1). All kerf depths $d_{\mathrm{K}}$ were measured using an optical measurement device MicroProf MPR 100 by FRT GMBH, Bergisch Gladbach, Germany. Three measurements were conducted per run.

For the high-speed recording experiments, the camera was placed in front of the specimens, which were prepared in convex and concave shapes with a radius of $r=30 \mathrm{~mm}$ and a depth of $l_{\mathrm{d}}=1 \mathrm{~mm}$. The length of the specimen was $l_{\mathrm{W}}=60 \mathrm{~mm}$ (Fig. 2a). The specimens were fixed in between two acrylic glass panes which had a squared shape. Thus, a convex and concave kerf was constructed which enables the recording of the AWJ effects in the kerf with the high-speed camera. Each video showed one specimen being machined once, number of passes $z=1$, by the AWJ from one edge to the other for all parameter combination given in Table 1, except the given angle of cut $\alpha_{\mathrm{c}}$. Every video was analysed in regard to the opening angle of the jetlag as well as the opening angle of the jet forerun at several workpiece positions $p_{\mathrm{W}}$. Additionally, the ratio of the intensity of the jetlag and the jet forerun was evaluated. The analysed positions were set in 5-mm steps between the specimen's edges. Thus, 176 samples of the AWJ's distributions were collected. The high-speed camera used to perform recordings of these first cutting experiments was a FASTCAM SA1.1 by PHOTRON DEUTSCHLAND GMBH, Reutlingen. The FASTCAM SA1.1 records video data which allowed frame-by-frame analysis. This provided the possibility to select valid image data by manually choosing an appropriate frame. The video was recorded with 10,000 frames per second (fps) and a resolution of $512 \times 512$ pixels. For the lighting of the experimental setup, spotlights from the front and from the back were used to obtain sufficient brightness in the imagery (Fig. 2b).

The analogy tests were conducted applying the same test plan from the high-speed recording test regarding the parameters water pressure $p$, feed speed $v_{\mathrm{f}}$ and abrasive flow rate $\dot{m}_{\mathrm{A}}$. The setup was modified in a way that the angle of cut $\alpha_{\mathrm{c}}$ remains constant for one cut (Fig. 2d). Hence, the factor "Shape" (Table 1) was replaced by the constant angles of cut $\alpha_{\mathrm{c}(\mathrm{y})}$. The setup comprised a primary target part (PTP) 
Fig. 2 Experimental setup: a input and target values of the high-speed recording and application tests; $\mathbf{b}$ setup of the high-speed recording tests; $\mathbf{c}$ water jet machine HRX $160 \mathrm{~L}$ by STM STEIN-MOSER GMBH, Schweinfurt, Germany; d input and target values of the analogy test a)

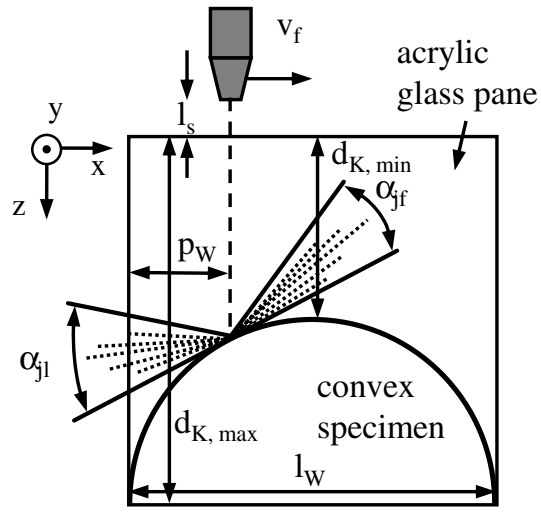

c)

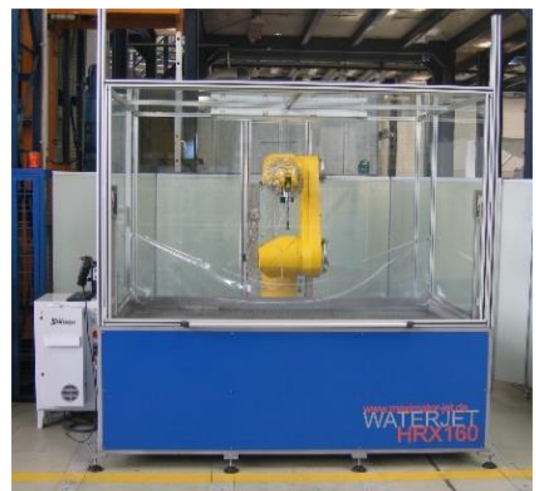

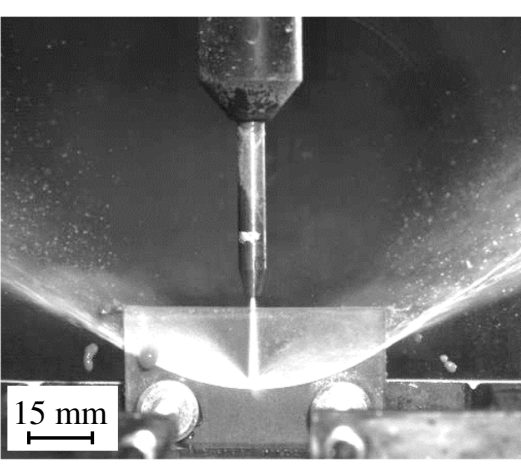

b)

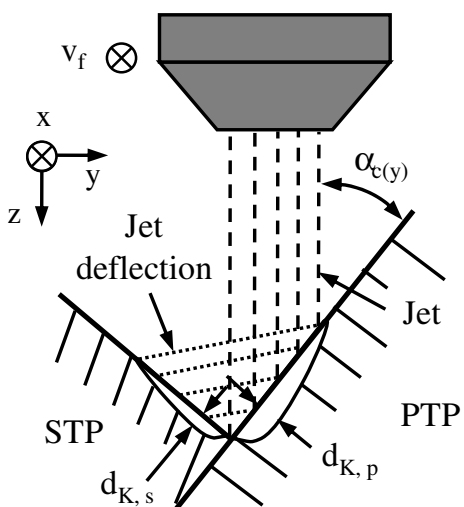

installed beneath the jet under the angles of cut $\alpha_{\mathrm{c}(\mathrm{y})}$. The jet moved along the $x$-axis causing a kerf and a jet deflection towards a secondary target part (STP). To investigate the intensity of the jet and the strength of its deflection, the resulting kerf depths on the primary $d_{\mathrm{K}, \mathrm{p}}$ and the secondary $d_{\mathrm{K}, \mathrm{s}}$ target parts were measured for 32 parameter settings.

The application tests comprise the milling of kerfs with variable kerf depth $d_{\mathrm{K}}(x)$. The tests were carried out by the adaption of the feed speed $v_{\mathrm{f}}\left(d_{\mathrm{K}}\right)$. The application tests were set up to mill the shapes described in the highspeed recording experiments with a radius of $r=30 \mathrm{~mm}$, a maximum kerf depth of $d_{\mathrm{K} \text {, } \max }=30 \mathrm{~mm}$ and a minimum kerf depth of $d_{\mathrm{K}, \min }=15 \mathrm{~mm}$ (Fig. 2a). The values for the feed speed $v_{\mathrm{f}}\left(d_{\mathrm{K}}\right)$ were derived using formula 1 with the coefficients and parameters given in Table 2. These parameters predict the kerf depth $d_{\mathrm{K}}$ of constant kerfs. The milling of variable kerf depths $d_{\mathrm{K}}(x)$ is likely to influence the kerf depth beyond the effects described by formula 1 . This influence can be expected since the cutting conditions are changed compared with the cutting of constant kerf depth. Therefore, a test plan (Table 2) was performed to find suitable parameters. The tests were preformed twice to ensure repeatability. In order to measure the kerf depths, the specimens were separated along the kerf using EDM. Afterwards, the kerf depth was measured on the remaining kerf profiles every $2 \mathrm{~mm}$.

Table 1 Experimental design for high-speed recording and analogy tests

\begin{tabular}{|c|c|c|c|c|c|}
\hline \multirow[t]{2}{*}{ Parameter } & & \multicolumn{4}{|c|}{ Levels } \\
\hline & & -- & - & + & ++ \\
\hline Water pressure $p$ & $\mathrm{MPa}$ & & 100 & 200 & \\
\hline Feed speed $v_{\mathrm{f}}$ & $\mathrm{mm} / \mathrm{min}$ & & 3000 & 5000 & \\
\hline Abrasive flow rate $\dot{m}_{\mathrm{A}}$ & $\mathrm{g} / \mathrm{min}$ & & 150 & 250 & \\
\hline Shape & - & & Convex & Concave & \\
\hline Angle of cut $\alpha_{\mathrm{c}(\mathrm{y})}$ & $\circ$ & 22.5 & 45 & 67.5 & 90 \\
\hline Number of passes $z$ & - & 1 & & & \\
\hline
\end{tabular}


Table 2 Experimental design for the application tests

\begin{tabular}{lll}
\hline Parameter & & Levels \\
\cline { 2 - 3 } & & - \\
\hline Water pressure $p$ & $\mathrm{MPa}$ & 100 \\
Max. feed speed $v_{\mathrm{f}}, \min$ & $\mathrm{mm} / \mathrm{min}$ & 2400 \\
Min. feed speed $v_{\mathrm{f}}, \max$ & $\mathrm{mm} / \mathrm{min}$ & 4800 \\
Shape & - & $\mathrm{Convex}$ \\
Abrasive flow rate $\dot{m}_{\mathrm{A}}$ & $\mathrm{g} / \mathrm{min}$ & 150 \\
Number of passes $z$ & - & 300 \\
Power coefficient $c_{\mathrm{p}}[4]$ & - & 7.49 \\
Coefficient $c_{1}[4]$ & - & 0.136 \\
Coefficient $c_{2}[4]$ & - & 0.101 \\
Coefficient $c_{3}[4]$ & - & $-0.22 \mathrm{e}^{-4}$ \\
\hline
\end{tabular}

\section{Results}

The main effects of the opening angles observed during the high-speed recording investigations are shown in Fig. 3. The diagram shows that in average the opening angles are approximately two times higher for the concave geometries. In addition, the opening angle of the jet forerun for concave

Process:

AWJ milling

Tools:

Garnet, Mesh 120, GMA

$\mathrm{d}_{\mathrm{O}}=0.25 \mathrm{~mm}$

$\mathrm{d}_{\mathrm{F}}=0.76 \mathrm{~mm}$

$\mathrm{l}_{\mathrm{F}}=76.2 \mathrm{~mm}$

Workpiece:

TNM-B1 $\gamma$-TiAl

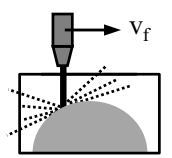

Process parameters:

$1_{\mathrm{s}}=2 \mathrm{~mm}$

$\mathrm{Z}=1$

A Opening angle of jetlag concave $\alpha_{\mathrm{jl}, \mathrm{a}}$

Opening angle of jetlag convex $\alpha_{\mathrm{jl}, \mathrm{x}}$

$\Delta$ Opening angle of jet forerun concave $\alpha_{\mathrm{jf}, \mathrm{a}}$

$\diamond$ Opening angle of jet forerun convex $\alpha_{\mathrm{jf}, \mathrm{x}}$

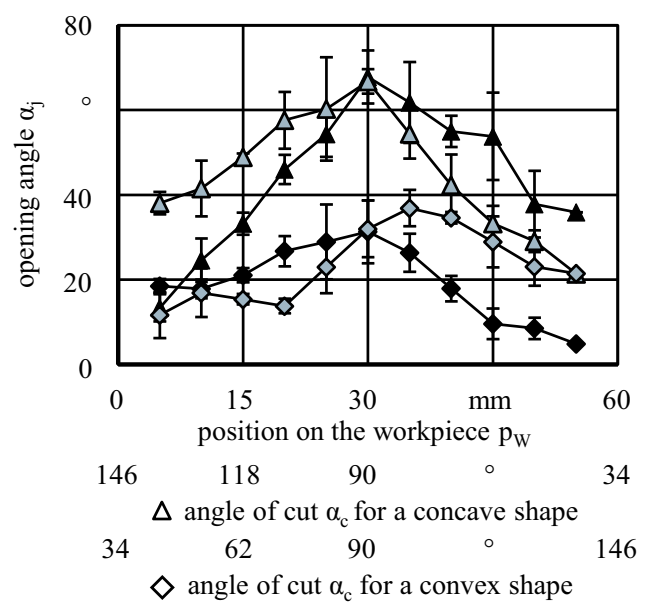

Fig. 3 Main effects of the jetlag and the jet forerun opening angles shapes $\alpha_{\mathrm{jf}, \mathrm{a}}$ is higher for high angles of cut $\left(\alpha_{\mathrm{c}}>90^{\circ}\right)$ at the beginning of the workpiece. The jetlag of the concave geometry $\alpha_{\mathrm{jl}, \mathrm{a}}$ shows a reversed behaviour and has higher opening angles for lower angles of cut $\left(\alpha_{\mathrm{c}}<90^{\circ}\right)$ at the end of the workpiece. The convex geometry shows an opposite behaviour compared with the concave geometry, considering the position on the workpiece $p_{\mathrm{W}}$. If the angle of cut $\alpha_{\mathrm{c}}$ is considered, the opening angle of the jet forerun $\alpha_{\mathrm{jf}, \mathrm{x}}$ is as well higher for high angles of cut $\alpha_{\mathrm{c}}>90^{\circ}$. In addition, the opening angle of the jetlag $\alpha_{\mathrm{jl}, \mathrm{x}}$ is higher for lower angles of cut $\alpha_{\mathrm{c}}>90^{\circ}$.

Besides the opening angles, the intensity of the jetlag and the jet forerun have been analysed. This observation resulted in a linear increase of the jetlag's intensity. The increase was found for the concave geometry between the position of the workpiece $p_{\mathrm{W}}=15$ to $45 \mathrm{~mm}$. Correspondingly, the effects are reversed for the convex geometry and the jet forerun.

The main effects of the kerf depth of the analogy test are depicted in Fig. 4. The diagram shows that the primary kerf depth $d_{\mathrm{K}, \mathrm{p}}$ increases with increasing angle of cut $\alpha_{\mathrm{c}}$, starting at $\alpha_{\mathrm{c}}=22.5^{\circ}$ until the kerf depth reaches a peak at $\alpha_{\mathrm{c}}=67.5^{\circ}$. For the angle of cut $\alpha_{\mathrm{c}}=90^{\circ}$, the kerf depth is reduced. The secondary kerf depth $d_{\mathrm{K}, \mathrm{s}}$ continuously decreases with increasing angle of cut $\alpha_{\mathrm{c}}$ until $d_{\mathrm{K}, \mathrm{s}}=0 \mathrm{~mm}$ at an angle of cut of $\alpha_{\mathrm{c}}=90^{\circ}$. Considering the setup of the tests, the results can be mirrored by $\alpha_{\mathrm{c}}=90^{\circ}$ to higher angles. Thus, the value of the angle of cut of $\alpha_{c}=67.5^{\circ}$ also applies for the angle of cut of $\alpha_{\mathrm{c}}=112.5^{\circ}$ and the angle of cut of $\alpha_{\mathrm{c}}=45^{\circ}$ for the angle of cut of $\alpha_{\mathrm{c}}=135^{\circ}$, and the angle of cut of $\alpha_{\mathrm{c}}=157.5^{\circ}$ equals the angle of cut of $\alpha_{\mathrm{c}}=22.5^{\circ}$. In Fig. 4, only the values of the angle of cut of $\alpha_{\mathrm{c}}=67.5^{\circ}$ are mirrored towards the angle of cut of $\alpha_{\mathrm{c}}=112.5^{\circ}$.

Figure 5 shows the results of the convex kerfs of the application experiments. The black line marks the target kerf. The arrow bars indicate the standard deviation $s$ of 
Process:

AWJ milling

Workpiece:

TNM-B1 $\gamma$-TiAl

Process parameters:

$1_{\mathrm{s}}=2 \mathrm{~mm}$

$\mathrm{z}=1$

$\Delta$ Primary kerf depth $\mathrm{d}_{\mathrm{K}, \mathrm{p}}$

- Secondary kerf depth $\mathrm{d}_{\mathrm{K}, \mathrm{s}}$

$\diamond$ Combined kerf depth $\mathrm{d}_{\mathrm{K}, \mathrm{p}+\mathrm{s}}$
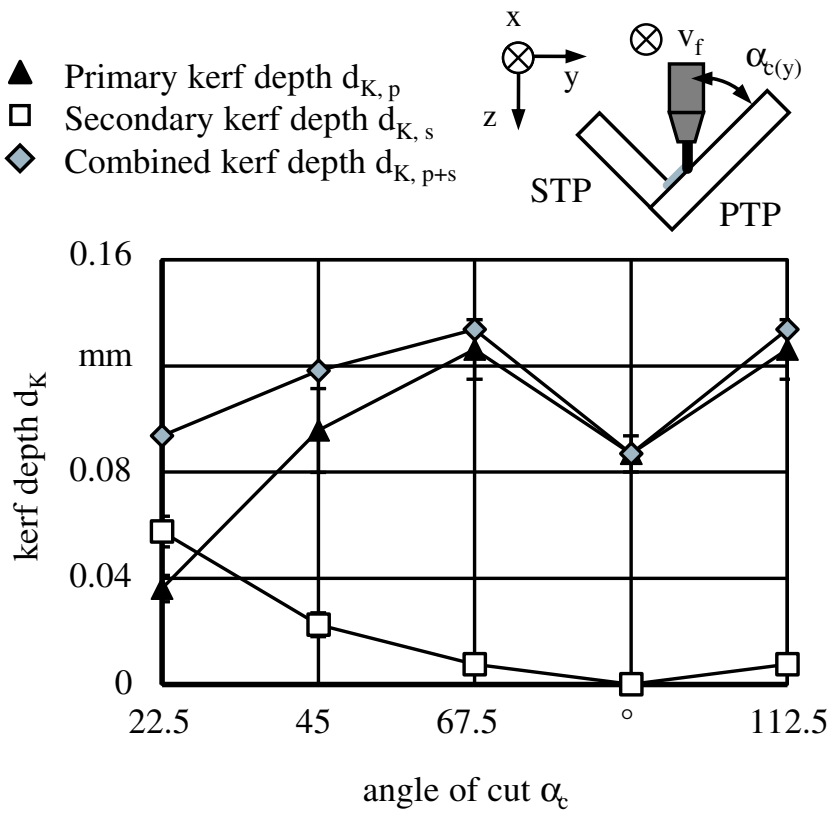

Fig. 4 Main effects of the kerf depth caused by the primary and the secondary jet

the kerf depth. The diagram shows that the results are well distributed around the target kerf. All kerfs seem to fit the target kerf in a sufficient manner. The difference caused by the parameter settings does not change the shape of the kerf and the average difference between lowest and the deepest kerf depth is $d_{\mathrm{K} \text {,diff }}=10.7 \mathrm{~mm}$. The best kerf regarding the convex shape seems to be the parameter with high feed speed and high water pressure $p$.

The kerf depth results of the concave shape are more diversified (Fig. 6). In comparison with the convex shape, the kerf depths of the different parameter combinations are much further apart, with an average difference of the kerf depth of $d_{\mathrm{K} \text {,diff }}=20.4 \mathrm{~mm}$. Furthermore, none of the parameter settings was able to fit the concave shape flawless regardless of the depth. Notably, most of the curves seem to have a flattened beginning and end.

\section{Discussion}

The results of the high-speed recording investigations demonstrated that there is a general difference regarding the opening angles between convex and concave geometries.

\section{Process:}

AWJ milling

Tools:

Garnet, Mesh 120, GMA

$\mathrm{d}_{\mathrm{O}}=0.25 \mathrm{~mm}$

$\mathrm{d}_{\mathrm{F}}=0.76 \mathrm{~mm}$

$1_{\mathrm{F}}=76.2 \mathrm{~mm}$

Workpiece:

TNM-B1 $\gamma$-TiAl

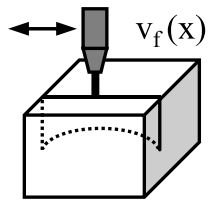

Process parameters:

$1_{\mathrm{s}}=2 \mathrm{~mm}$

$\mathrm{z}=300$

$\dot{\mathrm{m}}_{\mathrm{A}}=150 \quad \mathrm{~g} / \mathrm{min}$

$\Delta \mathrm{p}=100 \mathrm{MPa} ; \mathrm{v}_{\mathrm{f}, \max }=6000 \mathrm{~mm} / \mathrm{min}$

$\square \mathrm{p}=125 \mathrm{MPa} ; \mathrm{v}_{\mathrm{f}, \max }=6000 \mathrm{~mm} / \mathrm{min}$

$\diamond \mathrm{p}=125 \mathrm{MPa} ; \mathrm{v}_{\mathrm{f}, \max }=4800 \mathrm{~mm} / \mathrm{min}$

- $\mathrm{p}=100 \mathrm{MPa} ; \mathrm{v}_{\mathrm{f}, \max }=4800 \mathrm{~mm} / \mathrm{min}$

- target kerf

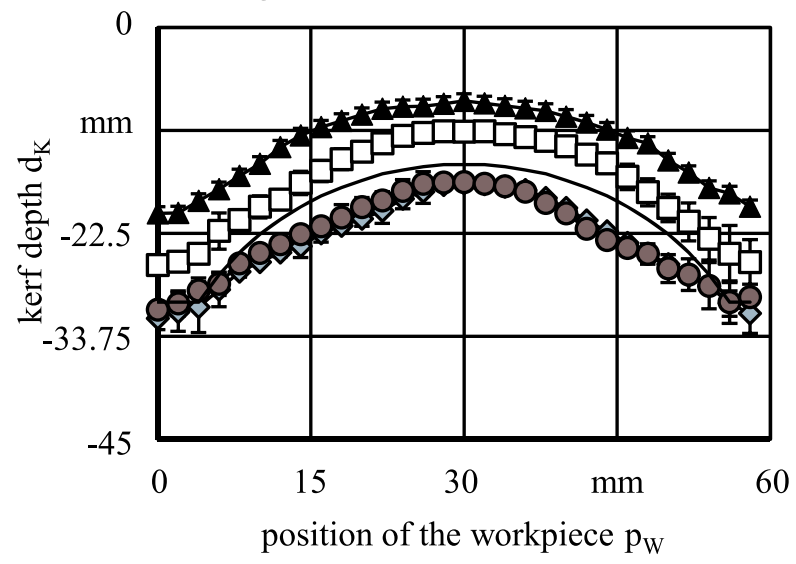

Fig. 5 Results of the application test: kerf depth $d_{\mathrm{K}}$ of the convex kerfs with variable kerf depth

Furthermore, the test reveals that all opening angles are low at very high $\alpha_{\mathrm{c}}=146^{\circ}$ and very low $\alpha_{\mathrm{c}}=34^{\circ}$ angles of cut. The cutting intensity of the jetlag or the jet forerun is likely to depend on the opening angles and the intensity of the jet deflection. If a point on the workpiece outside the primary jet is observed, high opening angles of the secondary jet have little impact on this point since the intensity is spread out. However, small opening angles might have a strong effect on this point. Consequently, the highest cutting potential of the secondary jet can be expected for convex geometries at very low angles of cut $\alpha_{\mathrm{c}}$ due to the jetlag and at very high angles of cut $\alpha_{\mathrm{c}}$ due to the jet forerun. High cutting potential can also be expected for concave geometries at very high angles due to the jet forerun and at very low angles due to the jetlag.

The results of the analogy test confirm this assumption and make this effect appraisable. The test reveals that the kerf depth created by the secondary jet increases with a highly increased or highly decreased angle of cut $\alpha_{\mathrm{c}}$. However, the test shows that the combined kerf depth does not increase due to the decreasing primary kerf depth. 


\section{Process: \\ AWJ milling}

Tools:

Garnet, Mesh 120, GMA

$\mathrm{d}_{\mathrm{O}}=0.25 \mathrm{~mm}$

$\mathrm{d}_{\mathrm{F}}=0.76 \mathrm{~mm}$

$1_{\mathrm{F}}=76.2 \mathrm{~mm}$

Workpiece:

TNM-B1 $\gamma$-TiAl

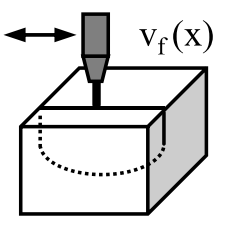

Process parameters:

$1_{\mathrm{s}}=2 \mathrm{~mm}$

$\mathrm{z}=300$

$\dot{\mathrm{m}}_{\mathrm{A}}=150 \quad \mathrm{~g} / \mathrm{min}$

$\Delta \mathrm{p}=100 \mathrm{MPa} ; \mathrm{v}_{\mathrm{f}, \max }=6000 \mathrm{~mm} / \mathrm{min}$

$\square \mathrm{p}=125 \mathrm{MPa} ; \mathrm{v}_{\mathrm{f}, \max }=6000 \mathrm{~mm} / \mathrm{min}$

$\diamond \mathrm{p}=125 \mathrm{MPa} ; \mathrm{v}_{\mathrm{f}, \max }=4800 \mathrm{~mm} / \mathrm{min}$

- $\mathrm{p}=100 \mathrm{MPa} ; \mathrm{v}_{\mathrm{f}, \max }=4800 \mathrm{~mm} / \mathrm{min}$

- target kerf

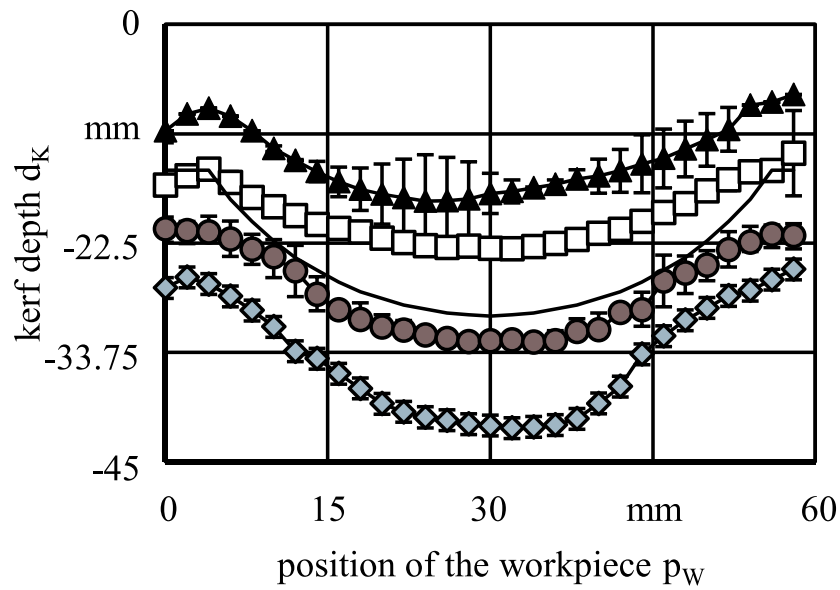

Fig. 6 Results of the application test: kerf depth $d_{\mathrm{K}}$ of the concave kerfs with variable kerf depth

The application test in Fig. 6 shows very different results compared with Fig. 5, although only the shape of the radius $r$ was changed from convex to concave. Consequently, the effects described above must interact with the cutting of variable kerf depths. The convex geometry is in average well reproduced by the approach. However, if the model [4] would be applicable, the parameter setting with $p=100 \mathrm{MPa}$ and $v_{\mathrm{f}, \max }=6000 \mathrm{~mm} / \mathrm{min}$ should have reproduced the shape accurately. The offset between the measured kerf depth $d_{\mathrm{K}, \mathrm{m}}$ and the target value can be explained by the fact that neither jetlag nor the jet forerun effects the kerf ground at any moment. Considering that even at constant kerf depths the jetlag clearly contributes to the deepening of the kerf [15], it seems that this effect is not present, or strongly reduced, for convex shapes. Hence, a factor needs to be considered which quantifies the difference between kerfs with constant kerf depths and kerfs with convex geometry. This convex geometry factor $f_{\mathrm{X}}(r)$ is most likely to depend on the radius $r$ of the convex geometry. For the given results, a convex geometry factor $f_{\mathrm{X}}(r=30 \mathrm{~mm})=1.6$ is calculated

with a standard deviation of $\mathrm{s}=0.1$. This factor can be expected to decrease for increasing radii until $f_{\mathrm{x}}=1$ and increase for even smaller radii.

In order to understand the large deviations of the kerf depths $d_{\mathrm{K}}$ for the concave geometry, it is necessary to consider the cutting effects of the jet at every point during the cutting for every stage of the kerf depth $d_{\mathrm{K}}$ (Fig. 7a). Firstly, the cutting of a constant kerf depth, angle of cut $\alpha_{\mathrm{c}}=90^{\circ}$, needs to be analysed. Since the shape of the kerf changes during the pass of the water jet an actual cutting angle $\alpha_{\mathrm{c}, \text { real }}$ occurs and can be estimated from the geometrical conditions. Figure $7 \mathrm{~b}$ demonstrates that the real cutting angle can be calculated to be $\alpha_{\mathrm{c} \text {,real }}=84$, if a jet diameter of $d_{\mathrm{J}}=0.8 \mathrm{~mm}$ and a kerf depth of $d_{\mathrm{K}} 1=0.086 \mathrm{~mm}$ is assumed for an angle of cut of $\alpha_{\mathrm{c}}=90^{\circ}$ and the number of passes $z=1$. Consequently, the results shown in Fig. 4 should be reduced by $\alpha_{\mathrm{c}}-\alpha_{\mathrm{c} \text {,real }}=6^{\circ}$ in order to correlate with the results of the variable kerf depths $d_{\mathrm{K}}(x)$. Following this idea, the expected kerf depth $d_{\mathrm{K}}$ is depicted in Fig. 7. Figure 7 shows the expected kerf depth $d_{\mathrm{K}}$ starting from an adjusted angle of cut of $\alpha^{\prime}{ }_{\mathrm{c}}=90^{\circ}\left(\alpha_{\mathrm{c}}=84^{\circ}\right)$. In the diagram, the kerf depth for one pass $d_{\mathrm{K} 1}$, taken from Fig. 4 , is shown in percent. This $100 \%$ value is linked to the calculation of formula 1. The diagram in Fig. 7c shows that if a higher angle is strived, the kerf depth for a pass $d_{\mathrm{K}} 1$ is lower than the expectation by formula 1 at first. Once an adjusted angle of cut of $\alpha^{\prime}{ }_{\mathrm{c}}=103$ is reached, the kerf depth for a pass $d_{\mathrm{K} 1}$ reaches again its target value given by formula 1 . Afterwards, the kerf depth per pass $d_{\mathrm{K} 1}$ is higher than the calculation with a peak at the angle of cut of $\alpha^{\prime}{ }_{c}=120^{\circ}$. In addition to the kerf depth per pass $d_{\mathrm{K} 1}$, the average cumulated kerf depth $d_{K, \mathrm{c}}$ is introduced. This value represents the expected deviation of the kerf depth $d_{\mathrm{K}}$ from the kerf depth given by formula 1 representing $100 \%$. Consequently, also the average cumulated kerf depth $d_{\mathrm{K}, \mathrm{c}}$ is lower than the expected value for the first passes $z$. The average cumulated kerf depth $d_{\mathrm{K}, \mathrm{c}}$ fits with the expectation at an adjusted angle of cut of $\alpha^{\prime}{ }_{c}=112^{\circ}$. From this point forward, every additional pass increases the kerf depth $d_{\mathrm{K}}$ disproportionately. Thus, the kerf becomes deeper than expected by the prediction.

In conclusion, the model for constant kerf depths $d_{\mathrm{K}}$ [4] only fits for the adjusted angle of cut of $\alpha^{\prime}{ }_{\mathrm{c}}=90^{\circ}$ and $\alpha^{\prime}{ }_{\mathrm{c}}=112^{\circ}$. Between these values, the kerfs are too low. For higher adjusted angle of cut of $\alpha^{\prime}$, the kerfs are too high. Thus, the results of Fig. 6 can be explained. Lower AWJ parameter settings, e.g. a water pressure of $p=100 \mathrm{MPa}$ and a feed speed of $v_{\mathrm{f}}=6000 \mathrm{~mm} / \mathrm{min}$, cause a slower growth. Consequently, most of the cutting happens in the area below the adjusted angle of cut of $\alpha^{\prime}{ }_{\mathrm{c}}=103^{\circ}$ resulting in a reduced kerf depth $d_{\mathrm{K}}$. On the other hand, AWJ parameter settings with a higher water pressure $p$ allow a quick transition to the adjusted angle of cut of $\alpha^{\prime}{ }_{\mathrm{c}}=103^{\circ}$ and above causing 
a)

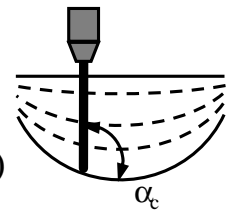

b) $\frac{\mathrm{d}}{\mathrm{T}}$
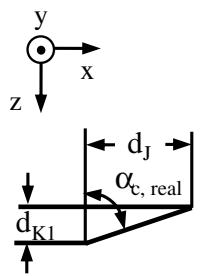

- Kerf depth for one pass $\mathrm{d}_{\mathrm{K} 1}$

- Average cumulated kerf depth $\mathrm{d}_{\mathrm{K}, \mathrm{c}}$

- Concave geometry factor $f_{a}\left(\alpha_{c}^{\prime}\right)$

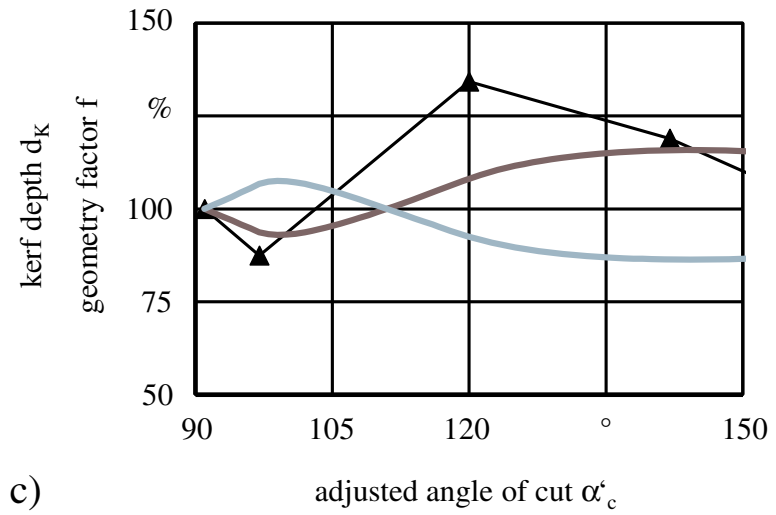

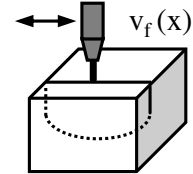

Process:

AWJ milling

Tools:

Garnet, Mesh 120, GMA

$\mathrm{d}_{\mathrm{O}}=0.25 \mathrm{~mm}$

$\mathrm{d}_{\mathrm{F}}=0.76 \mathrm{~mm}$

$1_{\mathrm{F}}=76.2 \mathrm{~mm}$

Workpiece:

TNM-B $1 \gamma$-TiAl

$1_{\mathrm{W}}=60 \mathrm{~mm}$

Process parameters:

$1_{\mathrm{s}}=2 \mathrm{~mm}$

Fig. 7 Effects during the cutting of concave kerfs: a kerf formation; $\mathbf{b}$ real cutting angle $\alpha_{\mathrm{c}, \text { real }}$; $\mathbf{c}$ kerf depth for a pass $d_{K 1}$, average cumulated kerf depth $d_{K, c}$, concave geometry factor $f_{a}$

a kerf deeper than predicted. This deliberation provides a reasonable explanation for the large deviation of the kerf depth $d_{\mathrm{K}}$ for concave geometries.

In order to predict these effects, a concave geometry factor $f_{\mathrm{a}}\left(\alpha_{\mathrm{c}}^{\prime}\right)$ can be implemented. This concave geometry factor $f_{\mathrm{a}}\left(\alpha_{\mathrm{c}}^{\prime}\right)$ depends on the desired angle of cut $\alpha_{\mathrm{c}}$. Since the radius $r$ of the concave geometry effects the angle of cut $\alpha_{\mathrm{c}}$, the concave geometry factor $f_{\mathrm{a}}$ also depends on the

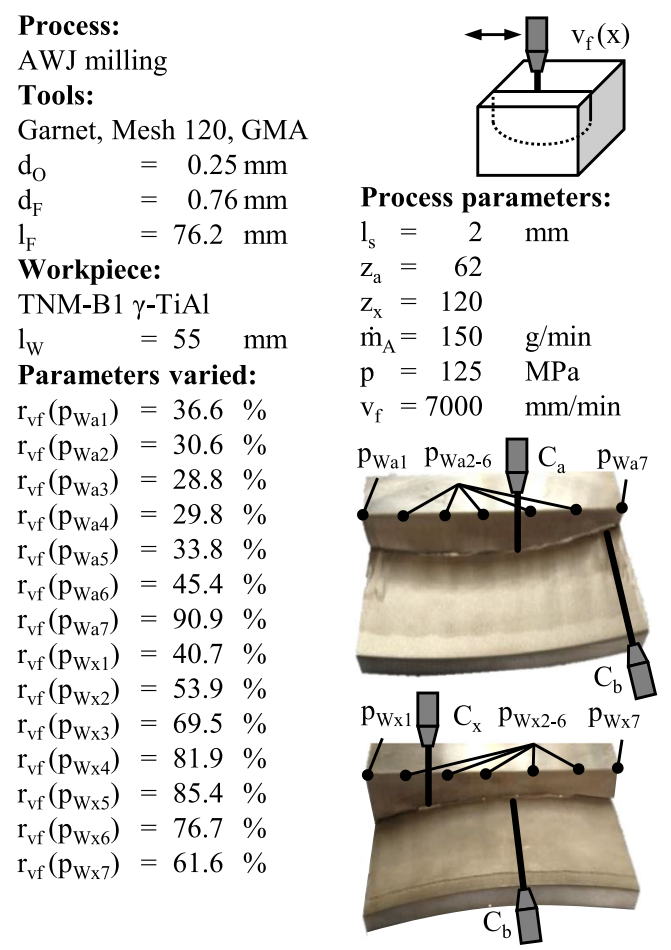

Fig. 8 Validation test of the geometry factors radius $r$. As a first approximation the factor $f_{\mathrm{a}}\left(\alpha^{\prime}{ }_{\mathrm{c}}\right)$ can be derived from the average cumulated kerf depth $d_{\mathrm{K}, \mathrm{c}}$. The factor is given in Fig. 7.

A final test was conducted to validate the ability of the concave geometry factor $f_{\mathrm{a}}$ and the convex geometry factor $f_{\mathrm{x}}$. Therefore, the shape of a turbine blade was implemented using a convex geometry factor $f_{\mathrm{x}}=1.15$ (Fig. 8). In addition, the concave geometry factor $f_{\mathrm{a}}$ was calculated and implemented for every point on the workpiece $p_{\mathrm{W}}$. The relative velocities $r_{\mathrm{vf}}$ calculated by both geometry factors are given in Fig. 8, along with all other parameters applied. The cuts along the turbine blade $C_{\mathrm{b}}$ were as well conducted by the AWJ. Since there is no kerf depth variation, the formula 1 has been applied without further adjustments. This test reveals that the deviation $e$ of the kerf depth to the target kerf is less than $e=0.5 \mathrm{~mm}$. Hence, the application of the geometry factors allows the manufacturing of precise variable kerf depths using the feed speed $v_{\mathrm{f}}$ as control parameter.

\section{Conclusion}

The objective of this investigation was to identify and evaluate the effects that occur during the cutting of variable kerf depths $d_{\mathrm{K}}(x)$ using abrasive water jet machining. Three investigations, including a cutting observation using a highspeed camera, an analogy test and an application test, have been conducted, measured and analysed. The paper presents and discusses the effects observed in the highspeed recording tests and the interactions of the effects during the cutting of the kerfs. The main results can be summarized as follows: 
- A concave geometry factor $f_{\mathrm{a}}$ and a convex geometry factor $f_{\mathrm{x}}$ have been introduced to describe the difference between the constant and variable kerf depths

- The convex geometry factor adjusts the decreased effects of the jet deflection and jet forerun for convex shapes. Consequently, the convex geometry factor depends on the radius $r$ and increases with decreasing radii.

- The more complex relation of convex shapes are compensated by the concave geometry factor $f_{\mathrm{a}}\left(\alpha^{\prime}{ }_{\mathrm{c}}\right)$. This factor accounts for the variations of the adjusted angle of cut $\alpha^{\prime}{ }_{\mathrm{c}}$ and thus depends on the angle of cut $\alpha_{\mathrm{c}}$ and consequently on the radius $r$. Compared with the convex geometry factor, the concave geometry factor varies for every point over a concave kerf.

- In combination, both factors allow the adjustment of the parameters of a constant kerf depth for variable kerf depths. As a result, the geometric possibilities for near-net-shape fabrication with the AWJ are extended allowing the manufacturing of the shape of a turbine blade.

- Thus, this AWJ milling operation can help to efficiently machine difficult-to-cut materials such as titanium aluminides and foster the efficiency improvements associated with these materials.

Funding Open Access funding enabled and organized by Projekt DEAL. This paper is based on results acquired in the project DFG UH 100/165-3, which is kindly supported by the Deutsche Forschungsgemeinschaft (DFG).

Open Access This article is licensed under a Creative Commons Attribution 4.0 International License, which permits use, sharing, adaptation, distribution and reproduction in any medium or format, as long as you give appropriate credit to the original author(s) and the source, provide a link to the Creative Commons licence, and indicate if changes were made. The images or other third party material in this article are included in the article's Creative Commons licence, unless indicated otherwise in a credit line to the material. If material is not included in the article's Creative Commons licence and your intended use is not permitted by statutory regulation or exceeds the permitted use, you will need to obtain permission directly from the copyright holder. To view a copy of this licence, visit http:// creativecommonshorg/licenses/by/4.0/.

\section{References}

1. Hashish M (1984) A modeling study of metal cutting with abrasive waterjets. J Eng Mater Technol 1984:88-100
2. Zeng J, Kim TJ (1992) Development of an abrasive waterjet kerf cutting model for brittle materials. Jet Cutting Technol 13:483501. https://doi.org/10.1007/978-94-011-2678-6_33

3. Liu X, Liang Z, Wen G, Yuan X (2019) Waterjet machining and research developments: a review. Int J Adv Manuf Tech 102:1257-1335. https://doi.org/10.1007/s00170-018-3094-3

4. Uhlmann E, Männel C (2019) Modelling of abrasive water jet cutting with controlled depth for near-net-shape fabrication. Procedia CIRP 81:920-925. https://doi.org/10.1016/j.procir.2019.03.228

5. Putz M, Dix M, Morczinek F, Dittrich M (2018) Suspension technology for abrasive waterjet (AWJ) cutting of ceramics. Procedia CIRP 77:367-370. https://doi.org/10.1016/j.procir.2018.09.037

6. El-Hofy M, Helmy MO, Escobar-Palafox G, Kerrigan K, Scaife R, El-Hofy H (2018) Abrasive water jet machining of multidirectional CFRP laminates. Procedia CIRP 68:535-540. https://doi.org/10.1016/j.procir.2017.12.109

7. Klocke F, Schmitt R, Zeis M, Heidemanns L, Kerkhoff J, Heinen D, Klink A (2015) Technological and economical assessment of alternative process chains for blisk manufacture. Procedia CIRP 35:67-72. https://doi.org/10.1016/j.procir.2015.08.052

8. Hashish M (1988) Turning, milling and drilling with abrasivewaterjets, 9th, International Symposium on Jet Cutting Technology 113-131

9. Fowler G, Shipway P, Pashby I (2005) Abrasive water-jet controlled depth milling of Ti6Al4V alloy - an investigation of the role of jet-workpiece traverse speed and abrasive grit size on. J Mater Process Technol 161:407-414

10. Kong MC, Axinte D, Voice W (2010) Aspects of material removal mechanism in plain waterjet milling on gamma titanium aluminide. J Mater Process Technol 210:573-584

11. Klocke F, Schreiner T, Schüler M, Zeis M (2018) Material removal simulation for abrasive water jet milling. Procedia CIRP 68:541-546. https://doi.org/10.1016/j.procir.2017.12.110

12. van Bui H, Gilles P, Sultan T, Cohen G, Rubio W (2017) A new cutting depth model with rapid calibration in abrasive water jet machining of titanium alloy. Int J Adv Manuf Tech 93:1499-1512. https://doi.org/10.1007/s00170-017-0581-x

13. Axinte DA, Karpuschewski B, Kong MC, Beaucamp AT, Anwar S, Miller D, Petzel M (2014) High energy fluid jet machining (HEFJet-mach): from scientific and technological advances to niche industrial applications. CIRP Ann Manuf Technol 63: 751-771. https://doi.org/10.1016/j.cirp.2014.05.001

14. Laurinat A (1994) Abtragen mit Wasserabrasivinjektorstrahlen. Dissertation, Universität Hannover

15. Faltin F (2018) Endkonturnahe Schruppbearbeitung von Titanaluminid mittels Wasserabrasivstrahlen mit kontrollierter Schnitttiefe. Dissertation, Technische Universität Berlin

16. Uhlmann E, Männel C, Flögel K, Faltin F (2017) Case study on possible productivity improvements of waterjet turning operations. WaterJet Technology Association, 2017 WJTA-IMCA Conference: A1

17. Uhlmann E, Männel C (2018) 3D-Vorkonturierung mittels Wasserabrasivstrahl. ZWF Zeitschrift für wirtschaftlichen Fabrikbetrieb 113:479-483. https://doi.org/10.3139/104.111950

Publisher's note Springer Nature remains neutral with regard to jurisdictional claims in published maps and institutional affiliations. 